\title{
Subseasonal hydrometeorological ensemble predictions in small- and medium-size mountainous catchments: Benefits of the NWP approach
}

Samuel Monhart ${ }^{1,2,3}$, Massimiliano Zappa ${ }^{1}$, Christoph Spirig ${ }^{2}$, Christoph Schär ${ }^{3}$, and Konrad Bogner ${ }^{1}$

$5{ }^{1}$ Swiss Federal Institute for Forest, Snow and Landscape Research WSL, Mountain Hydrology and Mass Movements, Birmensdorf, Switzerland

${ }^{2}$ Federal Office of Meteorology and Climatology MeteoSwiss, Climate Prediction, Zurich-Airport, Switzerland ${ }^{3}$ ETH Zurich, Institute for Atmospheric and Climate Science, Zurich, Switzerland

Correspondence to: Samuel Monhart (Samuel.Monhart@wsl.ch)

10 Supplement to the Manuscript|
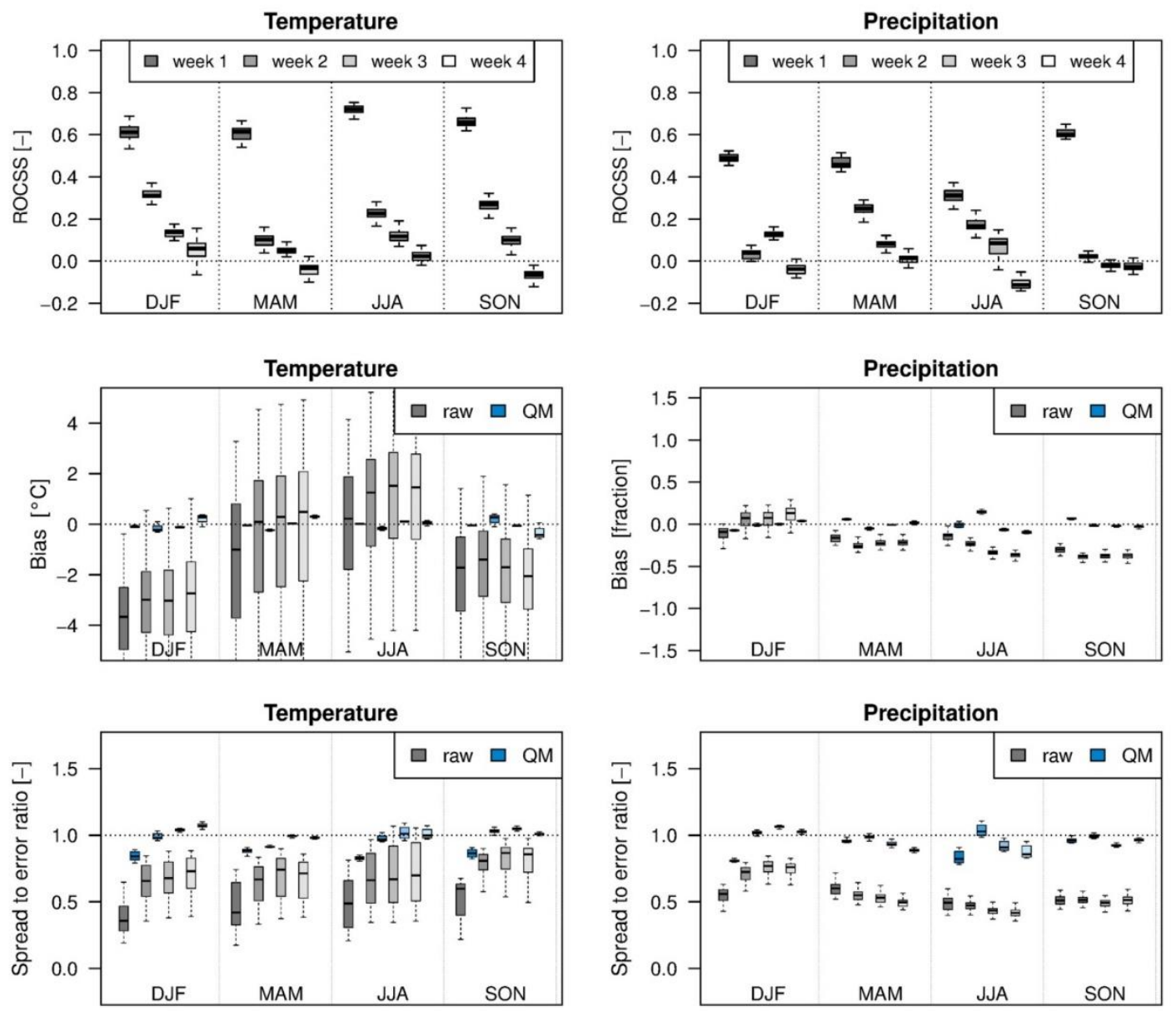

Figure S 1: ROCSS, Bias and Spread to error ratio for temperature and precipitation reforecast in the Verzasca catchment. 
Temperature
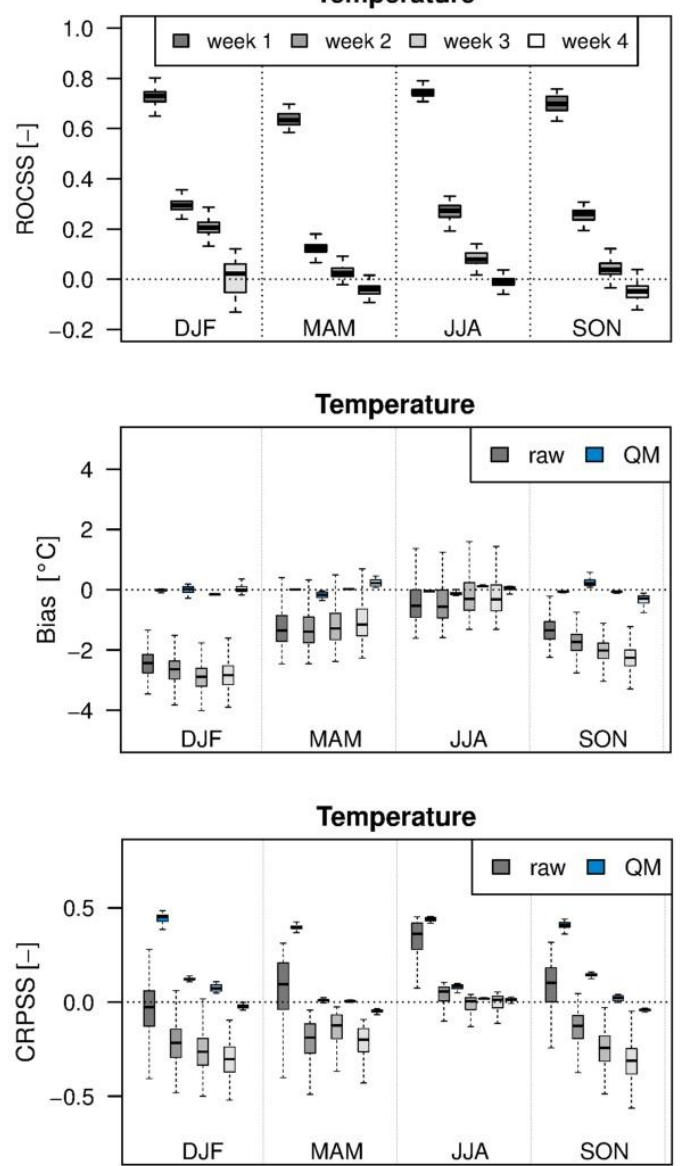

Temperature

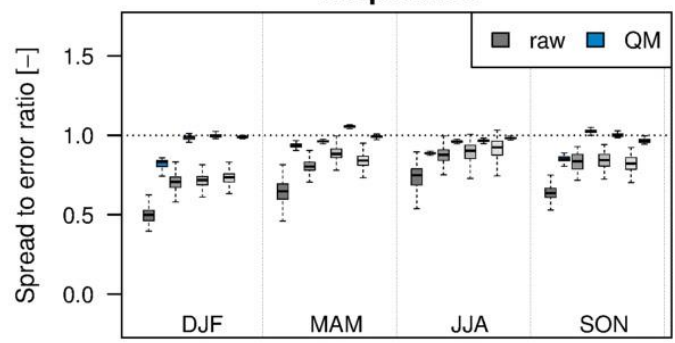

Precipitation

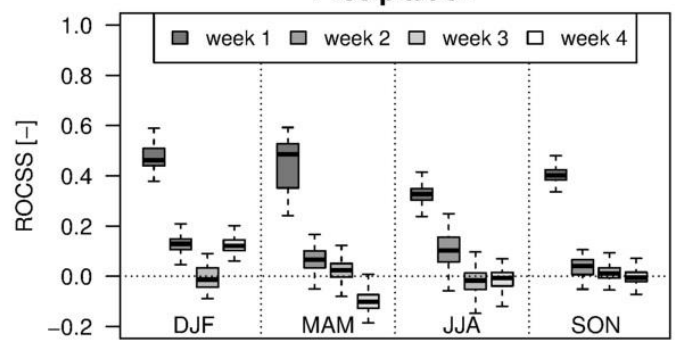

Precipitation

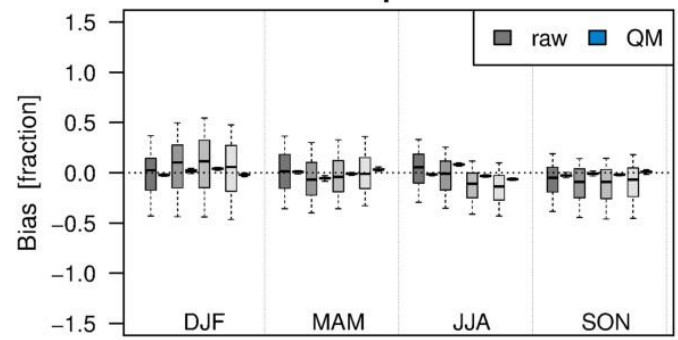

Precipitation

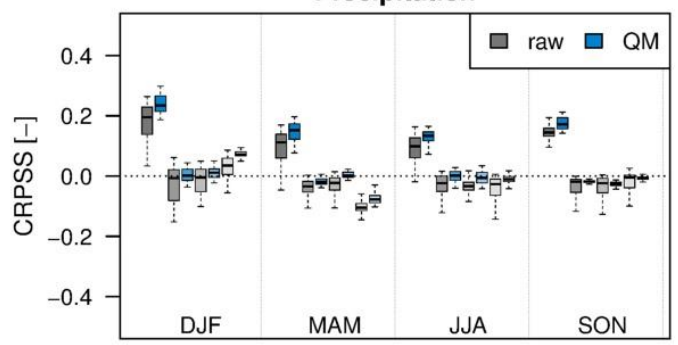

Precipitation

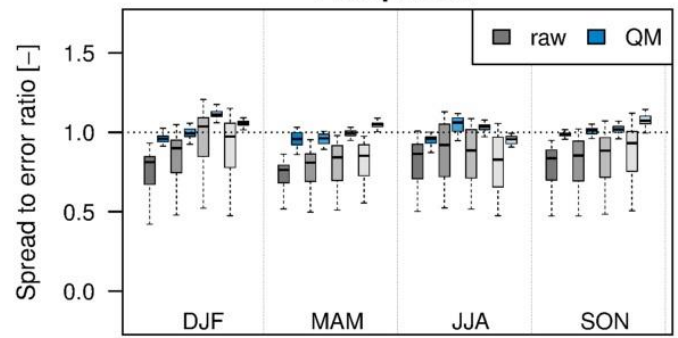

Figure S 2: Same as Figure S 1 but for the Thur catchment. In addition to Figure S1, the CRPSS is shown here as well. 
Temperature

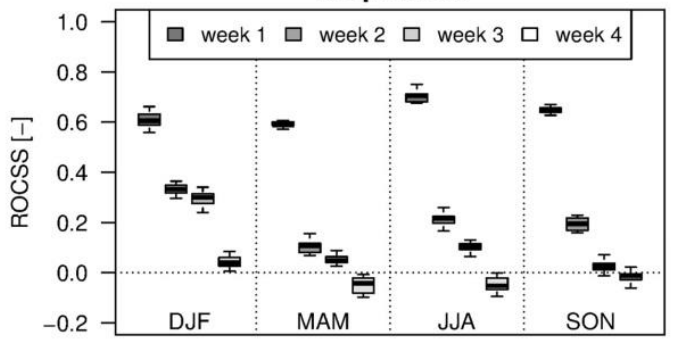

Temperature

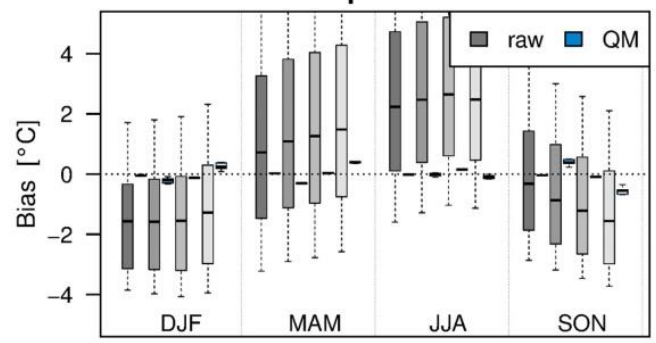

Temperature

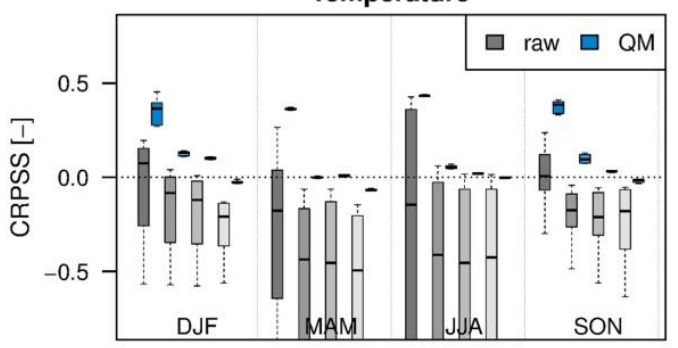

Temperature

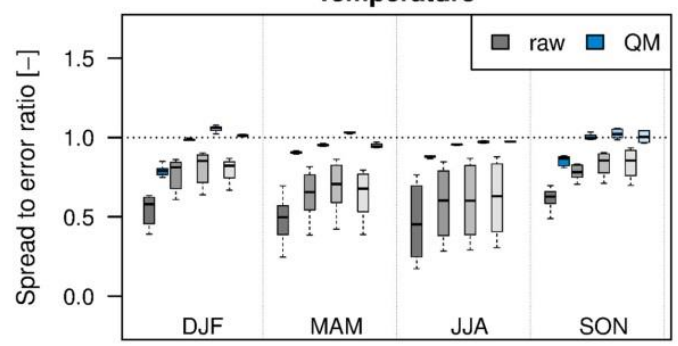

Precipitation
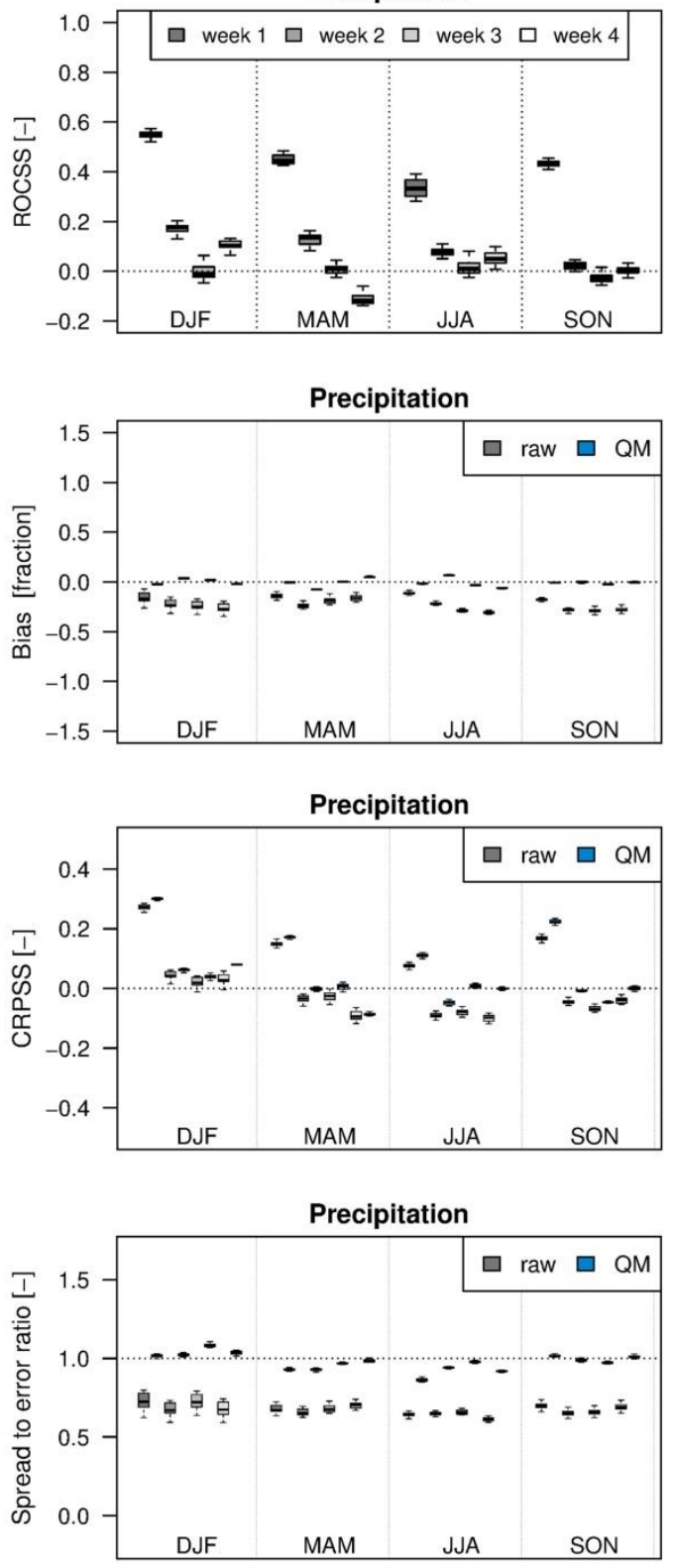

Figure S 3: Same as Figure S 2 but for the Klöntal catchment. 
Thur -- Murg

Full year
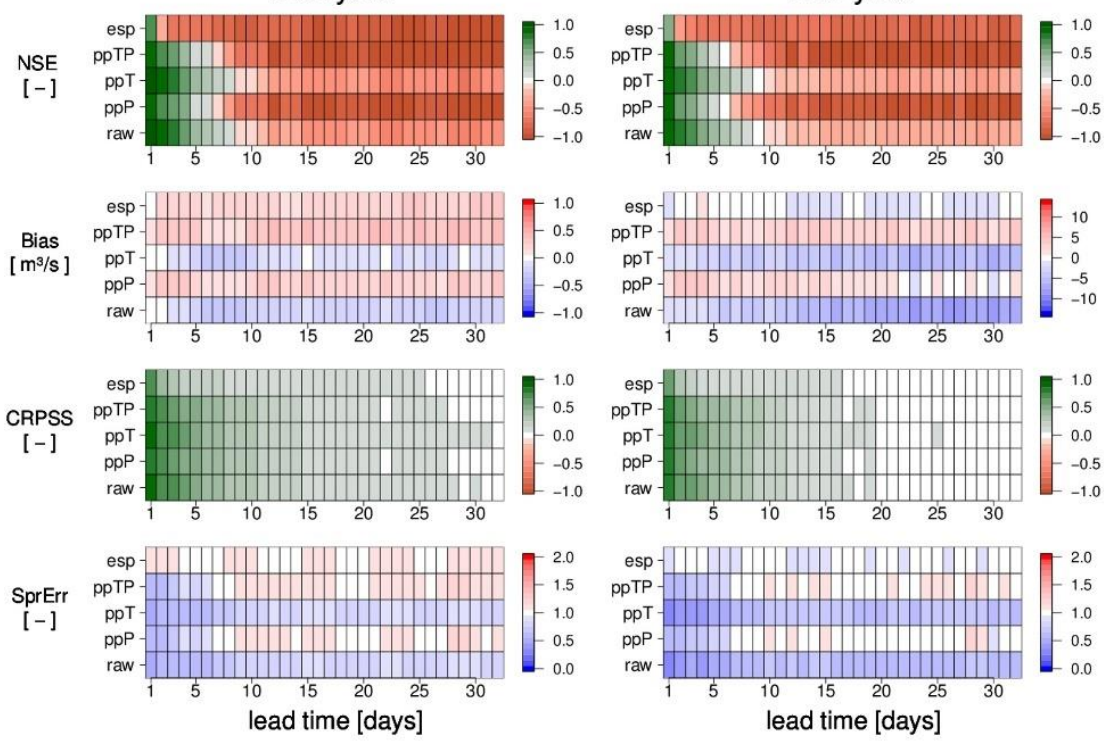

Thur -- Halden

Full year
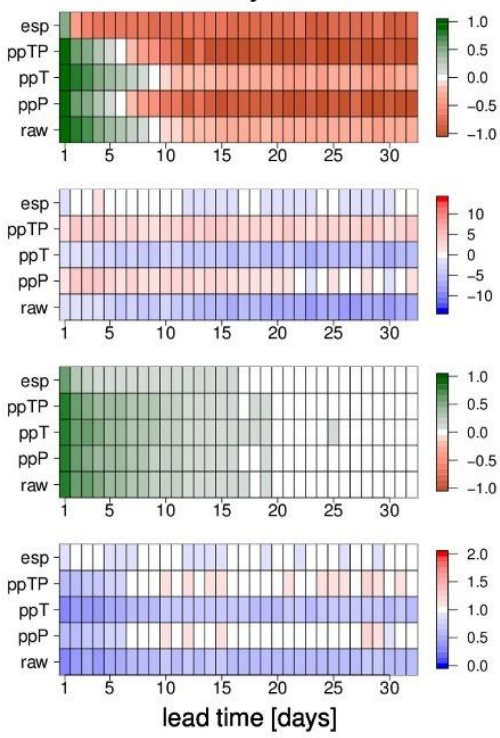

Figure S 4: As in Figure 4 but for the Thur subcatchments Murg and Halden. 
Klöntal

DJF
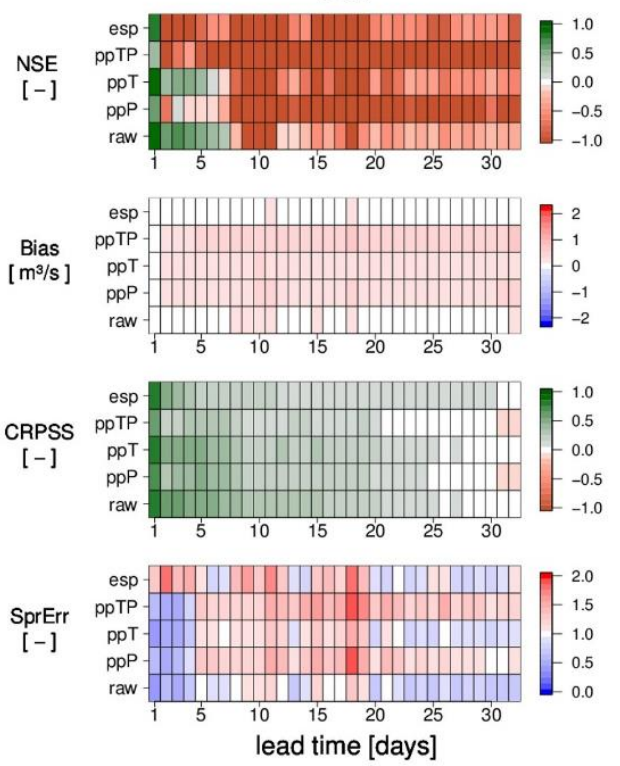

Thur

DJF
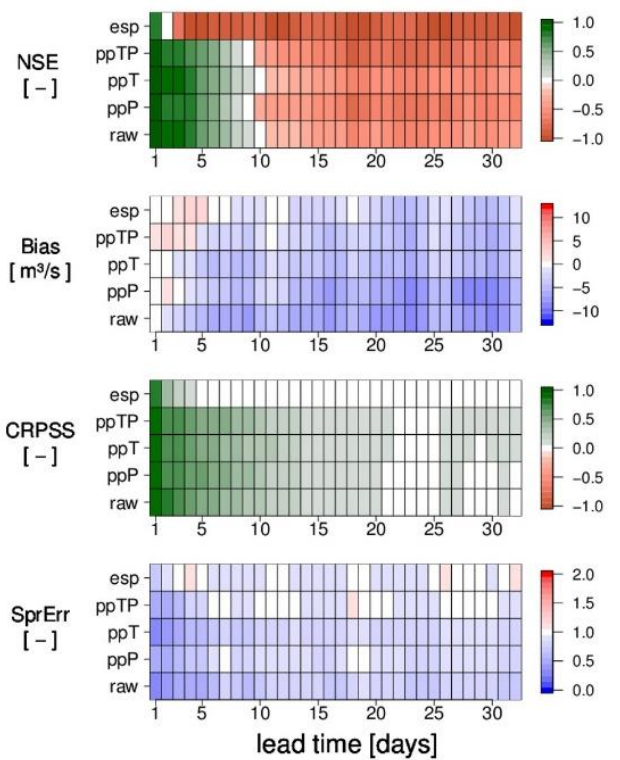

Klöntal

JJA
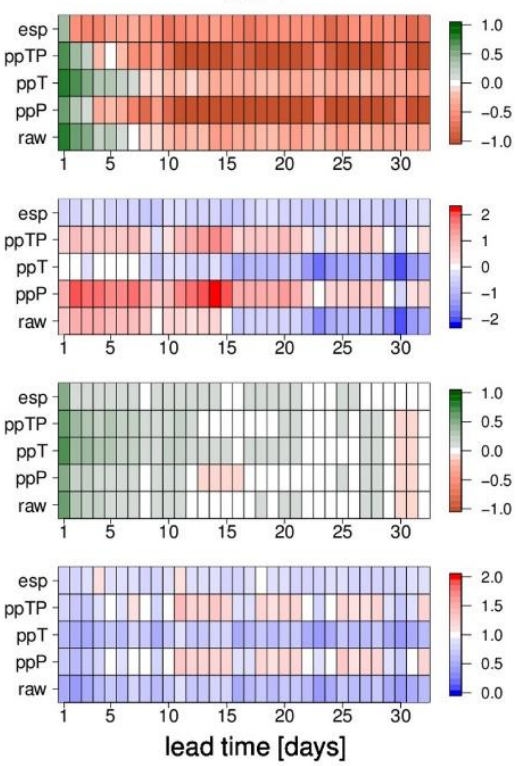

Thur

JJA
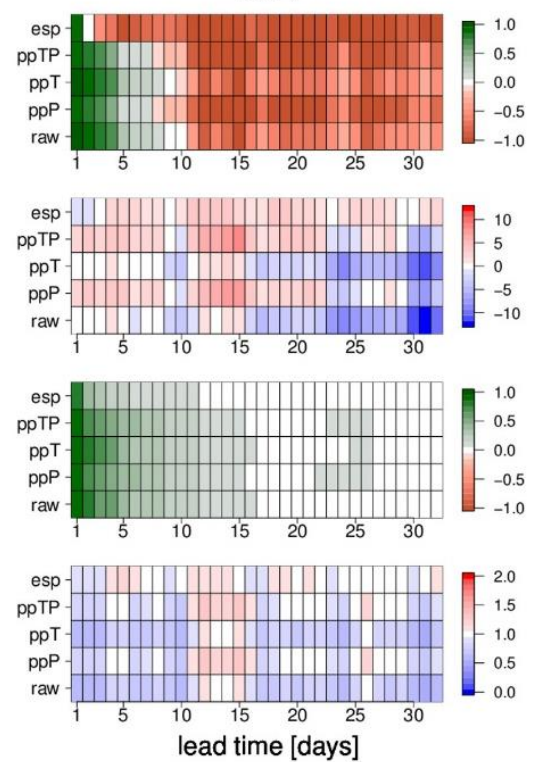

Klöntal

SON
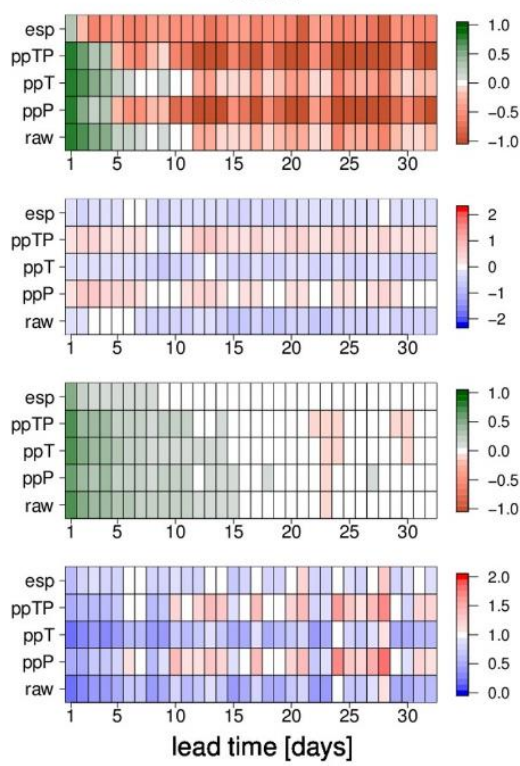

Thur

SON
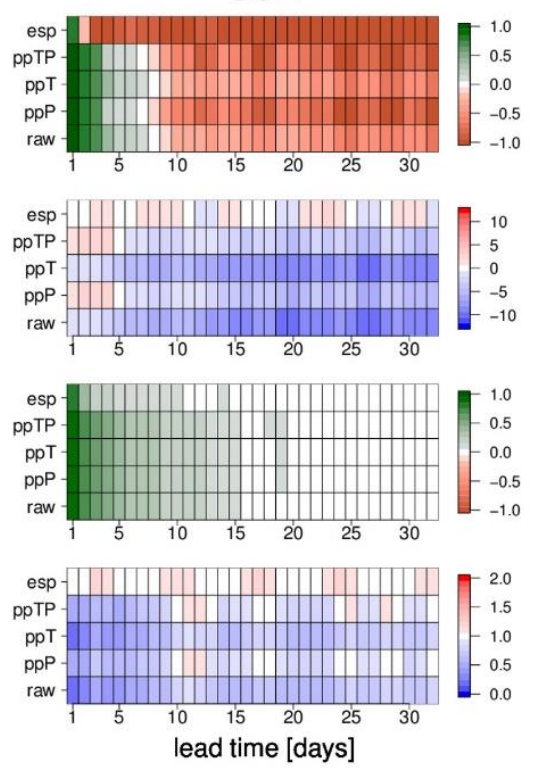

Figure S 5: As in Figure 6 but for the remaining seasons DJF, JJA and SON. 
Klöntal

FullYear
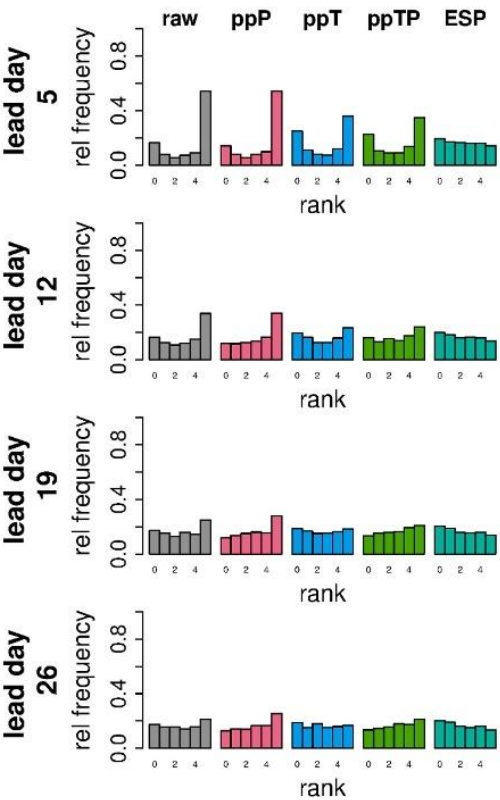

Thur

FullYear
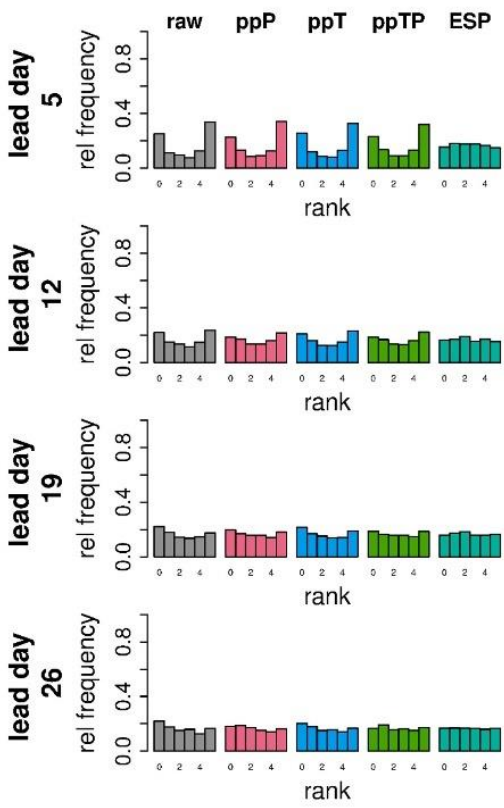

KIöntal

MAM
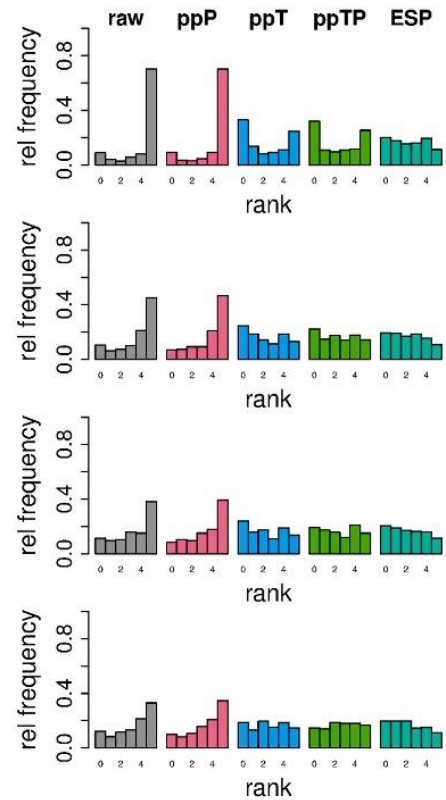

Thur

MAM
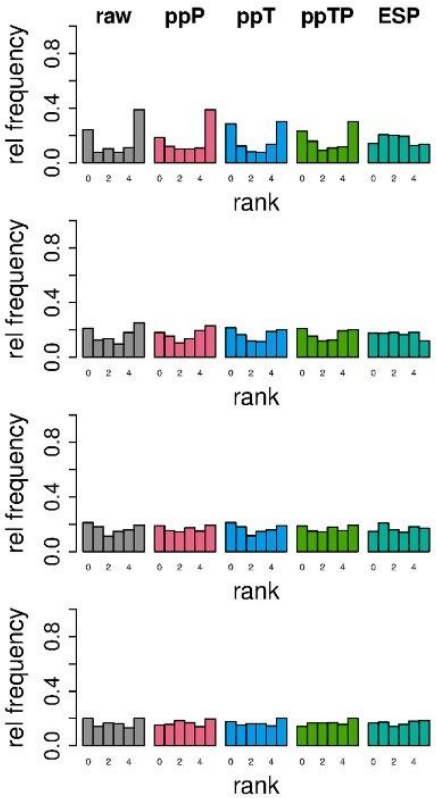

Figure S 6: As in Figure 7 but for the Klöntal and the Thur 
Klöntal -- DJF

SWE above $1500 \mathrm{~m}$ a.s.l.
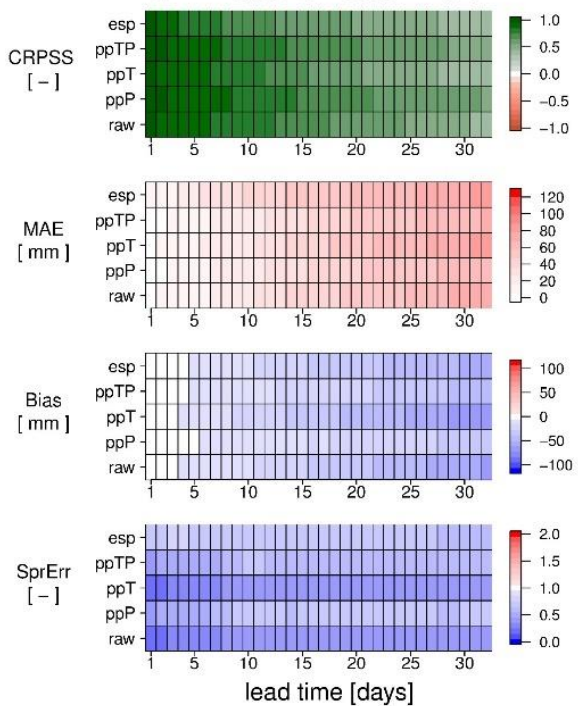

Klöntal -- MAM

SWE above $1500 \mathrm{~m}$ a.s.I.
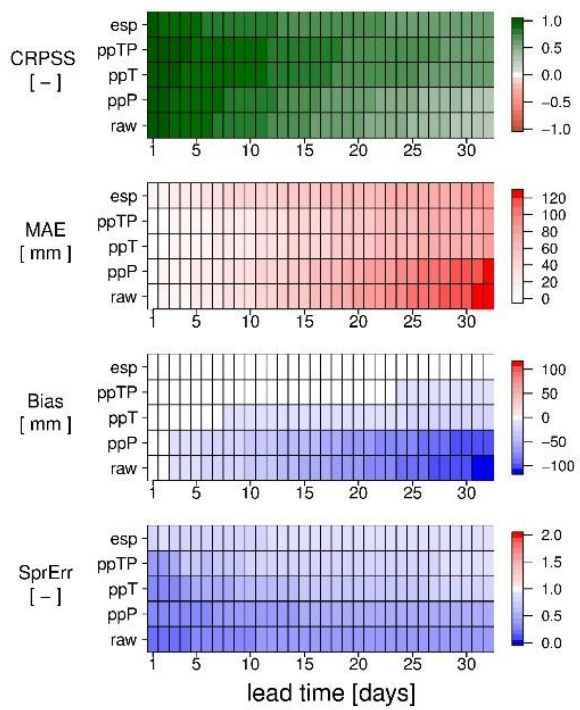

Klöntal -- DJF

SWE below $1500 \mathrm{~m}$ a.s.I.
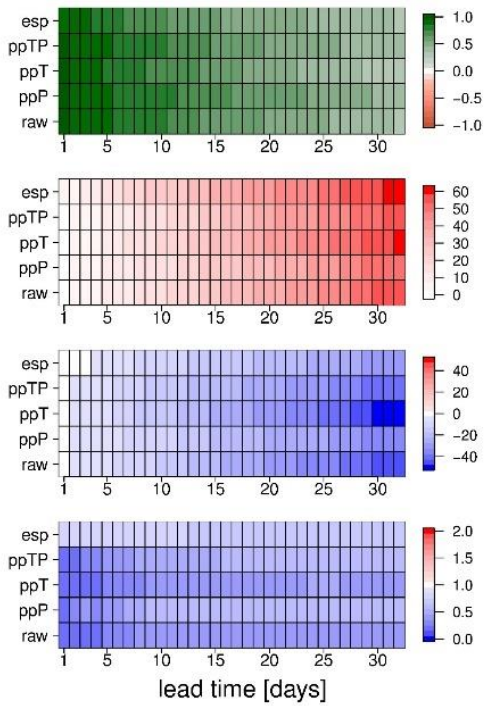

Klöntal -- MAM

SWE below $1500 \mathrm{~m}$ a.s.l.
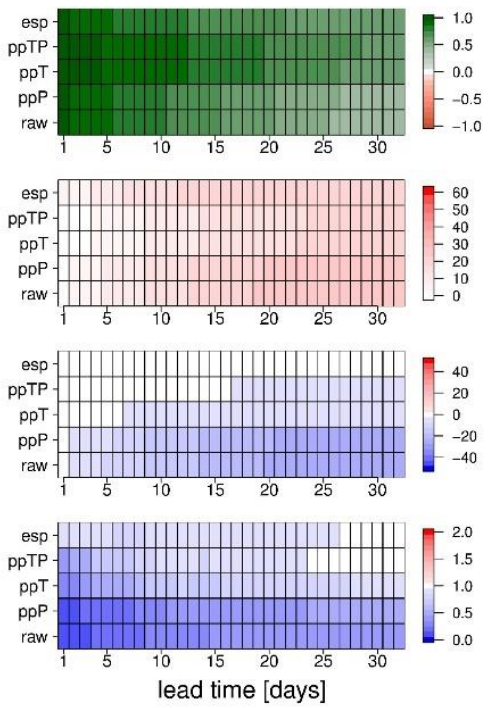

Figure S 7: As in Figure 8 but for DJF and MAM in the Klöntal catchment. 
Thur -- MAM

SWE below $1500 \mathrm{~m}$ a.s.I.

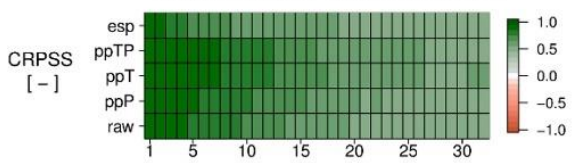

MAE

$[\mathrm{mm}$ ]
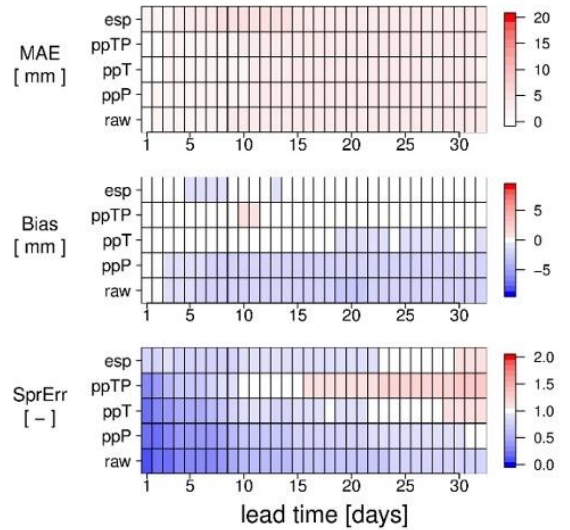

Thur -- DJF

SWE above $1500 \mathrm{~m}$ a.s.I.
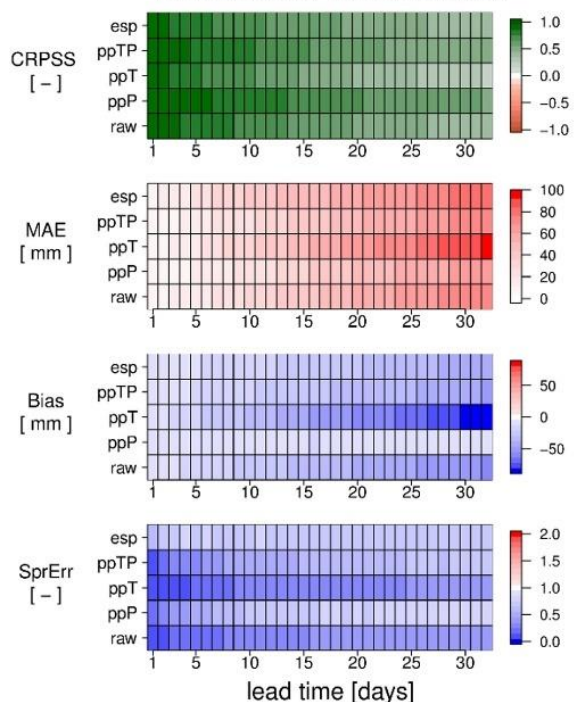

Thur -- MAM

SWE above $1500 \mathrm{~m}$ a.s.l.
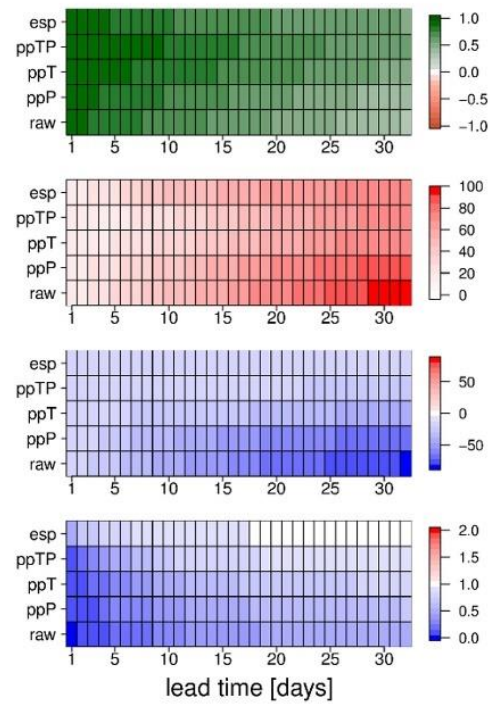

Thur -- DJF

SWE below $1500 \mathrm{~m}$ a.s.I.
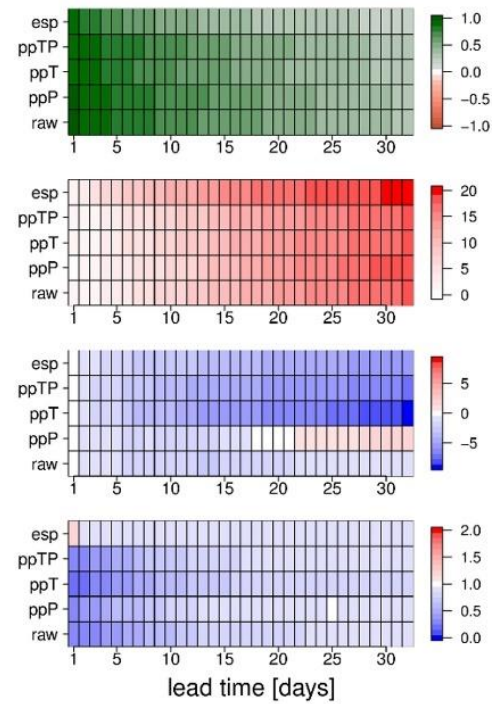

Figure S 8: As in Figure 8 but for DJF and MAM in the Thur catchment. 
DJF

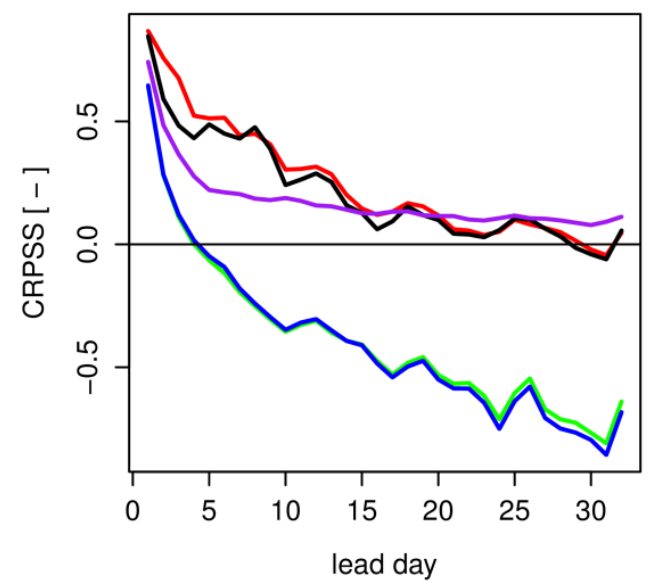

DJF

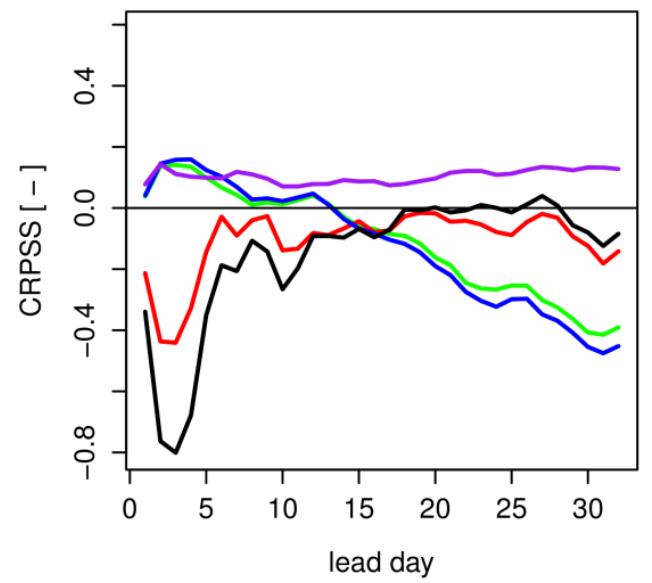

Figure S 9: CRPSS for the different prediction configurations ESP (purple), raw (green), ppP (blue), ppTG (red), ppTP (black). On the left for the predictions verified against the reference simulation and on the right verified against the real observations.

Verzasca, initialization date: 2009-02-05

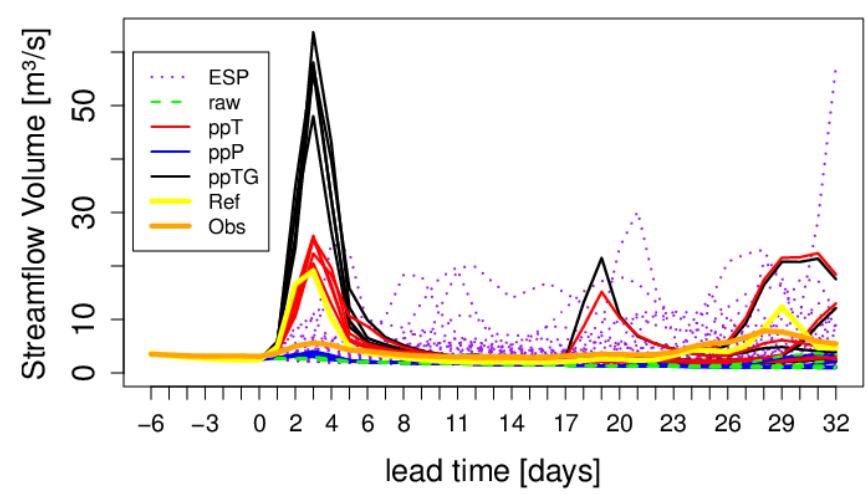

Figure S 10: Predicted streamflow for initialization date 2009-02-05 for all different versions (ESP, raw and pre-processed), the reference simulation and the observation. The initialization date is at lead day 0 , prior to this day only the reference simulation and observations are plotted. 

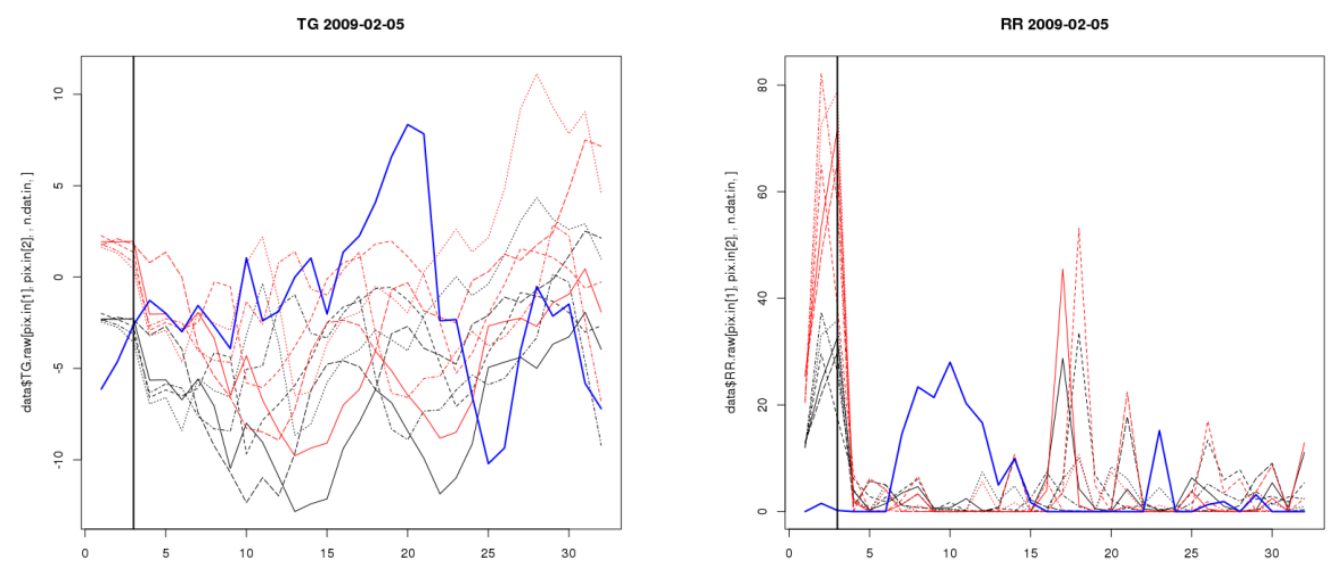

Figure S 11: Predicted raw (black) and corrected (red) reforecasts and corresponding observations (blue) for temperature on the left and precipitation on the right. The location is in the upper third of the catchment. 